\title{
IMPACTOS DO DISTANCIAMENTO SOCIAL POR COVID-19 NA COMUNICAÇÃO DE CRIANÇAS E ADOLESCENTES COM AUTISMO
}

\author{
IMPACTOS DE LA DISTANCIAMIENTO SOCIAL POR COVID-19 EN LA \\ COMUNICACIÓN DE NIÑOS Y ADOLESCENTES CON AUTISMO
}

\section{IMPACTS OF COVID-19 SOCIAL DISTANCING ON COMMUNICATION OF CHILDREN AND ADOLESCENTS WITH AUTISM}

\author{
Rosana Carla do Nascimento GIVIGI ${ }^{1}$ \\ Ane Cristine Hermínio CUNHA ${ }^{2}$ \\ Lara Lyss de Almeida BARRETO ${ }^{3}$ \\ Giovanna Santos da SILVA ${ }^{4}$ \\ Louise Carvalho da CONCEIÇÃO ${ }^{5}$
}

RESUMO: Durante a pandemia da Covid-19 uma das restrições foi o distanciamento social, que impactou a vida de todos. Este estudo objetivou analisar os efeitos do distanciamento social na comunicação de crianças e adolescentes com autismo. Trata-se de um estudo descritivo, de caráter transversal, no qual 322 pais ou responsáveis responderam um questionário on-line. Como resultado destaca-se: $96,60 \%$ dos participantes que estudam pararam de frequentar a escola; $88,20 \%$ dos respondentes avaliaram que houve mudança no comportamento da criança durante o período de distanciamento social; as mudanças foram negativas para $68,6 \%$ e positivas para $31,4 \% ; 46,70 \%$ apresentaram mudanças positivas na interação, 53,30\% negativas; 70,35\% estavam com mais contato visual e expressão facial, $29,65 \%$ estavam com menos; $48,45 \%$ entenderam que a linguagem e a comunicação estavam melhores, $51,55 \%$ que estavam piores. Conclui-se que pelo menos a metade das crianças e adolescentes investigados apresentaram piora nos aspectos mencionados, com implicações na comunicação, sendo importante que recebam apoio.

PALAVRAS-CHAVE: Comunicação. Infecções por coronavírus. Distanciamento social. Escola. Transtorno autístico. Família.

\footnotetext{
${ }^{1}$ Universidade Federal de Sergipe (UFS), Aracaju - SE - Brasil. Professora Associada do Departamento de Fonoaudiologia e do Programa de Pós-graduação em Educação - PPGED. ORCID: https://orcid.org/0000-00016592-0164. E-mail: rosanagivigi@gmail.com

${ }^{2}$ Universidade Federal de Campina Grande (UFCG), Cajazeiras - PB - Brasil. Professora Adjunta da Unidade Acadêmica de Educação. Doutoranda do Programa de Pós-Graduação em Educação (UFS). ORCID: https://orcid.org/0000-0003-1908-3320.E-mail: aneherminio@gmail.com

${ }^{3}$ Universidade Federal de Sergipe (UFS), Aracaju - SE - Brasil. Mestranda do Programa de Pós-Graduação em Educação - PPGED. ORCID: https://orcid.org/0000-0002-7525-5345 E-mail: fgalaralyss@gmail.com

${ }^{4}$ Universidade Federal de Sergipe (UFS), Aracaju - SE - Brasil. Graduanda em Fonoaudiologia. Bolsista de Iniciação Científica do CNPq. ORCID: https://orcid.org/0000-0002-2386-38599. E-mail: giovannasts07@gmail.com

${ }^{5}$ Universidade Federal de Sergipe (UFS), Aracaju - SE - Brasil. Graduanda em Fonoaudiologia. Bolsista de Iniciação Tecnológica. ORCID: https://orcid.org/0000-0001-8960-4676. E-mail: carvalho.loouise@gmail.com
} 
RESUMEN: Durante la pandemia de Covid-19, una de las restricciones fue el distanciamiento social, que afectó la vida de todos. Este estudio tuvo como objetivo comprender los efectos del distanciamiento social en la comunicación de niños y adolescentes con autismo. Se trata de un estudio descriptivo, de característica cruzada, en el que 322 padres o tutores respondieron a un cuestionario online. Como resultado, se destaca que el 96,60\% de los participantes que estudian dejaron de asistir a la escuela; el 88,20\% de los que respondieram evaluaron que hubo un cambio en el comportamiento del niño durante el periodo de distanciamiento social; el 68,6\% evaluaron que los cambios fueron negativos, el $31,4 \%$ que fueron positivos; el 46,70\% indicaron los cambios en la interacción como positivos, el 53,30\% como negativos; el 70,35\% estaban con más contacto visual y expresión facial, el 29,65\% dijeron que tenían menos; el 48,45\% entendieran que el lenguaje y la comunicación eran mejores, el 51,55\% que eran peores. Se concluye que al menos la mitad de los niños, niñas y adolescentes investigados empeoran en los aspectos conocidos, con implicaciones para la comunicación, y es importante que reciban apoyo.

PALABRAS CLAVE: Comunicación. Infecciones por coronavirus. Distanciamiento social. Colegio. Trastorno autista. Familia.

ABSTRACT: During the Covid-19 pandemic, one of the restrictions was social distancing, which impacted everyone's lives. This study aimed to analyze the effects of social distancing on the communication of children and adolescents with autism. This is a descriptive, crosssectional study, in which 322 parents or guardians answered an online questionnaire. As a result, the following stand out: $96.60 \%$ of the participants who study stopped attending school; $88.20 \%$ of the respondents assessed that there was a change in the child's behavior during the period of social distancing; $68.6 \%$ assessed that the changes were negative, $31.4 \%$ that they were positive; $46.70 \%$ indicated changes in the interaction as positive, $53.30 \%$ as negative; $70.35 \%$ stated that they had more eye contact and facial expression, $29.65 \%$ stated that they had less; $48.45 \%$ observed that language and communication were better, $51.55 \%$ that they were worse. We conclude that at least half of the children and adolescents investigated worsen in the known aspects, the Covid-19 pandemic had implications for the communication of children and adolescents with autism, and it is important that they receive support.

KEYWORDS: Communication. Coronavirus infections. Social distancing. School. Autistic disorder. Family.

\section{Introdução}

Em 2020, o mundo foi assolado por uma doença viral altamente contagiosa: a síndrome respiratória aguda grave do novo coronavírus (SARS-CoV-2). Os dados de vinte e três de setembro de 2021 apontam que há mais de 219 milhões de casos no mundo, com mais de 4,55 milhões de mortes. O Brasil, com 210,1 milhões de habitantes, somava mais de 21,3 milhões de casos e 592 mil óbitos por Covid-19 (WORLD HEALTH ORGANIZATION, 2021). 
A pandemia da Covid-19 impactou o mundo, mudou a rotina de famílias e as formas de se comunicar e se relacionar (DIAS-TRINDADE; CORREIA; HENRIQUES, 2020). Em 2020, devido à alta taxa de transmissão do SARS-CoV-2 e na ausência de um tratamento farmacêutico eficaz, e de uma vacina segura aprovada, o isolamento social total, efetivado enquanto quarentena, se apresentou como a única estratégia eficaz para conter o avanço da Covid-19 no Brasil e no mundo (HE et al., 2020; LAUER et al., 2020). No início de 2021 foram aprovadas as primeiras vacinas e no dia 17 de janeiro de 2021 foi vacinada a primeira pessoa no Brasil. A vacinação caminhou a passos lentos em vários países do mundo, incluindo o Brasil, e por essa razão não foi possível evitar uma $2^{\mathrm{a}}$ e até $3^{\mathrm{a}}$ onda da Covid-19 em muitos países. O Brasil vive atualmente (23/09/21) um momento em que a situação é considerada controlada, com uma média de 400 mortes diárias, mas se mantém o distanciamento social como uma das medidas de contenção da pandemia (WORLD HEALTH ORGANIZATION, 2021).

O distanciamento social se configura, entre outras medidas, com o fechamento de escolas, locais de trabalho, estradas, eventos públicos e privados, quarentena obrigatória para pessoas infectadas e não infectadas (LEWNARD; LU, 2020; KOO et al., 2020). Apenas é permitida a abertura de serviços considerados essenciais, segundo a legislação vigente.

Em Sergipe, o Decreto $n^{\circ} 40.567$ (SERGIPE, 2020a), regulamentou a suspensão de diversas prestações de serviço no setor público e privado em todo o estado. Para essa pesquisa, é sobressalente ressaltar a suspensão das atividades educacionais em todas as escolas das redes de ensino público e privado, o que perdurou até fevereiro de 2021, quando as escolas privadas retornaram, fechando novamente em março e reabrindo em maio. Já as escolas públicas abriram recentemente de forma híbrida. Os consultórios de fonoaudiologia, psicologia, terapia ocupacional, necessários para auxiliar o desenvolvimento de crianças com atraso, também seguiram fechados até julho de 2020. No primeiro semestre de 2020, só poderiam funcionar para prestação de serviços especializados enquadrados como urgência e emergência, observada a catalogação prevista nos conselhos de classe (SERGIPE, 2020b).

Foram imperativas as medidas de distanciamento impostas às famílias. Muitos tiveram que trabalhar em home office, as crianças tiveram que se limitar a brincar e estudar dentro de casa, bem como evitar contato social com amigos e familiares. As rotinas das famílias foram duramente modificadas. Para crianças que necessitam de ajuda profissional especializada com serviços de reabilitação, os consultórios voltaram a funcionar a partir de agosto de 2020, com uma série de restrições e protocolos de segurança. Quanto às escolas, seu fechamento seguiu por todo o ano letivo de 2020, uma média de quarenta semanas. 
Em 2021, a portaria $n^{0} 273 / 2020$ autorizou o funcionamento das escolas nas redes públicas e particular em Sergipe (SERGIPE, 2020c), o que também aconteceu em diversos outros estados. No entanto, no mês de março desse mesmo ano o Brasil viveu o maior colapso sanitário e hospitalar da história do país, com esgotamento do sistema de saúde nos 27 estados (FIOCRUZ, 2021). A gravidade dessa situação impôs novas medidas de restrição, com toque de recolher e, em alguns estados, lockdown (FIOCRUZ, 2021).

Nesse cenário pandêmico, o distanciamento social impõe novos modos de ser e viver. Para o desenvolvimento infantil, muitos são os prejuízos, uma nota de alerta da Sociedade Brasileira de Pediatria atentou para o estresse tóxico produzido pelo confinamento, que pode ocasionar: distúrbios do sono, baixa imunidade, atraso no desenvolvimento, depressão, baixo desenvolvimento escolar (SOCIEDADE BRASILEIRA DE PEDIATRIA, 2020a).

O estudo de Jiao et al. (2020), com 320 crianças e adolescentes na província de Shaanxi, na China, relatou que durante o distanciamento social as crianças e adolescentes apresentaram dificuldades funcionais e comportamentais. Dentre estas, aponta-se: a dependência excessiva dos pais, desatenção, preocupação, distúrbios do sono, falta de apetite, pesadelos, desconforto, agitação, irritabilidade. Wang et al. (2020) abordam que o distanciamento social e o fechamento prolongado das escolas provocaram danos à saúde das crianças, pois estas exercem baixa atividade física, possuem mais tempo de tela (o que afeta o desenvolvimento da linguagem e o social), dieta não saudável e sono irregular.

Quando se trata da pessoa com deficiência, percebe-se que esta sofre mais efeitos adversos decorrentes da pandemia da Covid-19. O estudo de Shakespeare, Ndagire e Seketi (2021) aponta que as pessoas com deficiência têm dificuldade de acessar os serviços de saúde e reabilitação imprescindíveis para seu tratamento. Isso corrobora com o risco de agravamento da sua condição de saúde, além dos impactos sociais advindos dos esforços em mitigar a pandemia. Os autores ressaltam também que os alunos com deficiência têm dificuldade no retorno à escola, visto que a situação gera insegurança das escolas e das famílias.

Nesse campo tão heterogêneo que compõem as pessoas com deficiência, este estudo buscou compreender a condição de crianças e adolescentes com Transtorno do Espectro do Autismo (TEA). O TEA é definido pelo Manual Diagnóstico e Estatístico de Transtornos Mentais (DSM-5) 5a . edição (AMERICAN PSYCHIATRIC ASSOCIATION, 2013) como um transtorno do neurodesenvolvimento caracterizado pelas seguintes condições: déficits persistentes na comunicação social e interação social, com déficits na reciprocidade socioemocional, déficits nos comportamentos comunicativos não verbais e déficits para desenvolver, manter e compreender relacionamentos. Outros critérios são os padrões 
repetitivos e restritos de comportamento, interesses e atividades, como fala, manuseio de objetos, movimentos motores repetitivos ou estereotipados, padrões ritualizados de comportamento verbal e não verbal, inflexibilidade quanto a rotinas, interesses fixos e restritos, interesse incomum por aspectos sensoriais do ambiente.

O TEA manifesta-se em todos os grupos socioeconômicos e em sujeitos de diversas etnias. É causado por combinação de fatores ambientais e genéticos. Sua prevalência é maior em meninos que em meninas, cerca de 4:1. Ao primeiro sinal de atraso no alcance das habilidades previstas para a faixa etária é indicado tanto o apoio escolar como a intervenção especializada para favorecer o desenvolvimento dessas crianças (SOCIEDADE BRASILEIRA DE PEDIATRIA, 2019).

São sintomas comportamentais no autismo: irritabilidade, agressividade, automutilação, ansiedade, hiperatividade, impulsividade, desatenção e insônia. Os déficits de comunicação incluem dificuldade na comunicação funcional, para iniciar ou responder uma conversa, tempo reduzido do contato visual. Quanto à comunicação não verbal, há pouca compreensão de gestos e mímica facial. No campo interacional, há dificuldade na brincadeira imagética, em se adequar aos contextos sociais, com diminuído interesse por pares. Quanto à ritualização do comportamento, há ecolalia, movimento estereotipado, preferência por um único objeto, interesses perseverativos em objetos, baixa tolerância a estímulos sensoriais (BRIET et al., 2017; OTTONI; MAIA, 2019).

De acordo com o Conselho Federal de Fonoaudiologia (2020), os casos de autismo não são enquadrados nos serviços de urgência e emergência. Nesse sentido, pacientes com esse diagnóstico seguiriam sem o apoio escolar e intervenção especializada necessária ao seu desenvolvimento, como preveem os manuais de orientação. Em situação de normalidade social, as crianças e adolescentes com autismo estariam nas escolas e expostos a atividades de reabilitação, que são essenciais ao seu desenvolvimento, durante muitas horas ao dia. Em 2020 isso foi impossibilitado, devido às medidas mais incisivas quanto ao isolamento e distanciamento social. Por mais que consultórios clínicos terapêuticos tenham sido autorizados a funcionar a partir do segundo semestre de 2020, muitas famílias não se sentiram seguras para esse retorno, e em 2021, o agravamento da pandemia e a calamidade do sistema de saúde impuseram restrições igualmente severas quanto ao isolamento e distanciamento social.

Como decorrência do confinamento, prevê-se que as dificuldades de comportamento e comunicação se agravem. As mudanças impostas devido à quarentena, como a necessidade de intensificação dos cuidados com higiene, a quebra de rotinas das terapias, o convívio íntimo e 
exclusivo com os familiares em casa, podem exacerbar os sintomas na comunicação e comportamentais. Assim, o objetivo deste trabalho foi compreender os efeitos do distanciamento social na comunicação de crianças e adolescentes com autismo.

\section{Metodologia}

Trata-se de um estudo descritivo, de caráter transversal. Este estudo foi aprovado pelo Comitê de Ética e Pesquisa (CEP) envolvendo seres humanos da Universidade Federal de Sergipe, CAAE: 33464320.9.0000.5546.

A pesquisa foi realizada através de um questionário feito a partir do Formulário Google e distribuído pela divulgação de um hiperlink. O questionário foi disponibilizado na forma on-line no período de 3 de julho a 11 de agosto de 2020. Junto ao questionário estava o termo de consentimento, portanto todos os participantes assinaram o termo, que informava o objetivo do estudo, seus procedimentos, sobre a participação voluntária e como fazer contato com os pesquisadores.

O questionário continha 21 questões, destas 19 eram questões assertivas (6 de resposta única, 5 dicotômicas, 8 questões de múltipla escolha) e 2 questões de resposta aberta divididas por categorias: (a) as características sociodemográficas e os aspectos psicossociais; (b) o impacto do distanciamento social, provocado pela pandemia da Covid-19, no comportamento da criança ou adolescente com autismo; e (c) o impacto do distanciamento social, provocado pela pandemia da Covid-19, na linguagem e na comunicação da criança ou adolescente com autismo. Neste artigo, serão incluídas as categorias (a) e (c).

\section{Participantes da Pesquisa}

Os participantes foram contactados através de listas e grupos disponíveis em redes sociais e sites de associações. Os respondentes foram pais ou responsáveis, ou profissionais autorizados pelos pais, de crianças e adolescentes de 2 a 19 anos com autismo. O diagnóstico de TEA foi por autodeclaração.

\section{Análise dos Dados}

Os dados foram submetidos à análise estatística e análise descritiva para caracterização dos participantes e efeitos do distanciamento social na comunicação da criança e adolescente com autismo. Foi realizada a análise descritiva e analítica dos dados. 
Os dados coletados foram colocados em planilha de dados do programa Excel for Windows 2013 e, posteriormente no programa Statistical Package for Social Sciences (SPSS), versão 16.0, com nível de significância de 5\% ( $\mathrm{p}>0,05)$. Foi considerado o perfil da amostra e sua descrição, levando em conta as variáveis do estudo.

\section{Resultados}

Os questionários da pesquisa foram respondidos por 322 participantes, sendo eles pais ou responsáveis, ou profissionais autorizados pelos pais de crianças e adolescentes. A seguir serão apresentados os resultados.

\section{Caracterização Sociodemográfica e Psicossocial}

Dentre os 322 respondentes, $263(81,7 \%)$ eram mães das crianças ou adolescentes, e $30(9,3 \%)$ eram pais. A grande maioria das crianças e adolescentes com autismo eram do sexo masculino (257) e o restante do sexo feminino (65).

Quanto à idade das crianças e adolescentes, variou de 2 a 19 anos, com a maioria (252) tendo entre 3 e 11 anos. Houve representação de todas as regiões do Brasil, com 210 (65,2\%) sendo do Nordeste, região em que foi desenvolvida a pesquisa, 61 do Sudeste, 31 no Sul, 11 no Norte e 9 na região Centro-Oeste.

As rendas variaram, mas merece destaque o fato de 22,7\% ganhar até um saláriomínimo e de 74,0\% ter renda até cinco mil reais. Das famílias pesquisadas, 55,65\% tiveram diminuição de renda durante a quarentena. Quanto à formação das famílias, a maioria tem 3 ou 4 membros (73,6\%). No primeiro semestre de distanciamento social, $4 \%$ das crianças e adolescentes com autismo estavam saindo, apesar de 69\% das famílias ter pelo menos um adulto saindo com frequência.

Retornando a rotina anterior das crianças e adolescentes, verifica-se que dos 322 participantes, 311 (96,60\%) estudam, e, além disso, 100\% deles faziam outras atividades semanais. As atividades que foram mais frequentes foram as artísticas, as esportivas e as terapêuticas. Como as crianças e adolescentes com autismo, habitualmente, fazem terapias de suporte, foram investigados os tratamentos mais frequentes antes da pandemia, e verificou-se que $71,73 \%$ faziam terapia fonoaudiológica, $62,42 \%$ terapia ocupacional e $70,18 \%$ acompanhamento psicológico. Durante o primeiro semestre do período pandêmico a grande 
maioria das famílias ficou sem esses suportes e tiveram atendimento de forma virtual apenas $13,0 \%, 14,9 \%$ e $13,3 \%$, respectivamente.

Quantificando todas as atividades que as crianças ou adolescentes executavam antes da pandemia, foi contabilizado 1.251 atividades, sabendo-se que uma mesma criança fazia mais de uma atividade. Durante a pandemia, o número de atividades caiu para 391, o que significa que apenas $31,25 \%$ das atividades foram mantidas durante período pandêmico.

Os participantes relataram que eram habituais, antes do distanciamento social, as atividades de lazer, em que as mais frequentes eram: visitar parentes ou amigos (235), brincar no parquinho (183), brincar na rua (151), passear no shopping (149), ir à praia (117). Com o distanciamento social, essas atividades foram substituídas por brincar dentro de casa ou no quintal, jogar no celular ou tablet, desenhar e assistir televisão. Outro dado importante é que das 322 crianças e adolescentes 211 ficaram brincando sozinhas e 194 brincando com adultos.

\section{O Impacto do Distanciamento Social na Linguagem e na Comunicação da Criança ou Adolescente com Autismo}

Inevitavelmente, a rotina das famílias foi modificada. A grande maioria das famílias (284) avalia que houve mudança no comportamento da criança durante o período de distanciamento social (Gráfico 1). Quanto às mudanças, $221(68,6 \%)$ avaliam que as mudanças foram negativas, e 31,4\% (101) que foram positivas.

Figura 1 - Avaliação se a criança/adolescente mudou o comportamento durante o distanciamento social

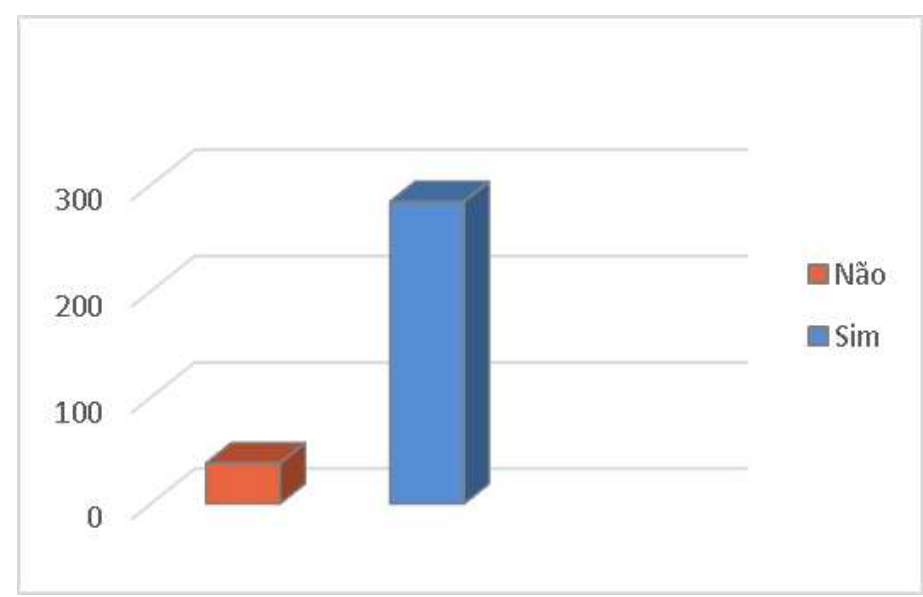

Fonte: Dados do questionário

Em relação à linguagem e comunicação, o questionário continha 15 alternativas, podendo ser marcada mais de uma alternativa. Essas questões estavam divididas em três 
grandes temáticas, a primeira relacionada à interação, a segunda a características paralinguísticas, a terceira diretamente relacionada à linguagem e comunicação. A primeira agrupava as seguintes questões: brincando melhor, interagindo melhor; e o inverso, com dificuldade em partilhar a brincadeira, interagindo com mais dificuldade. A segunda temática: com mais contato visual, com mais expressão facial; e o inverso, com menos contato visual, com menos expressão facial. A terceira temática agrupou as seguintes questões: respondendo melhor as perguntas, comunicando-se melhor, falando melhor; e o inverso, com falta de resposta a perguntas, com dificuldade para se comunicar, com repetição de palavras, frases, partes de músicas ou do que lhe é falado.

A análise das respostas foi feita a partir das três temáticas. Na primeira, relacionada à interação, foram 364 respostas. Dessas, 170 (46,70\%) participantes apontaram as mudanças na interação como positivas; e $194(53,30 \%)$ apontaram as mudanças de interação como negativas. Na segunda temática, relacionada às características paralinguísticas, foram um total de 300 respostas, em que $211(70,35 \%)$ dessas disseram que as crianças e adolescentes estavam com mais contato visual e mais expressão facial; e $89(29,65 \%)$ apontaram que as crianças e adolescentes estavam com menos contato visual e menos expressão facial. $\mathrm{Na}$ terceira temática, em relação à linguagem e comunicação, foram 551 respostas. A linguagem e comunicação foi entendida como melhor, durante o distanciamento social, por 267 (48,45\%) participantes, e como pior por 284 (51,55\%) participantes (Gráfico 2).

Figura 2 - Impacto do distanciamento social na linguagem e na comunicação da criança ou adolescente com autismo

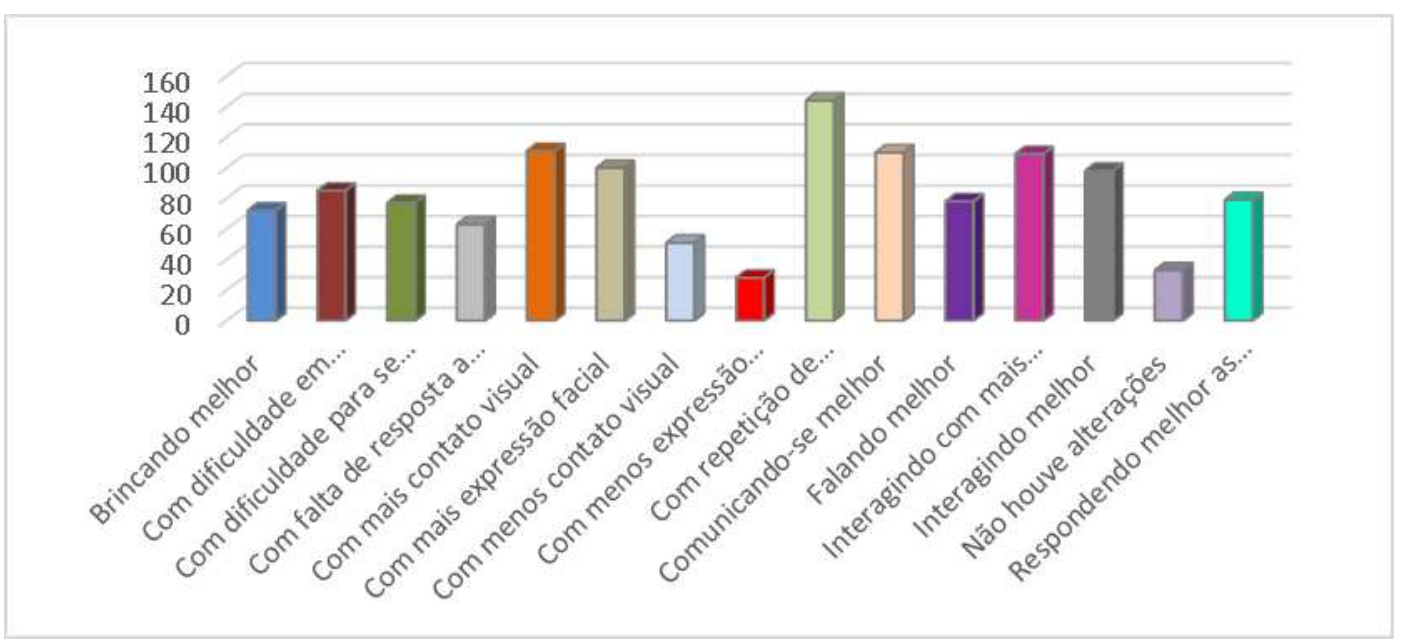

Fonte: Dados do questionário 


\section{Discussão}

Das características sociodemográfica e psicossocial, o primeiro aspecto a ser analisado será sobre os respondentes. Verificou-se que $81,7 \%$ eram mães das crianças ou adolescentes. Outros trabalhos de pesquisa constataram que no exercício das funções parentais a mãe é quase sempre a maior responsável pelos cuidados dos filhos, uma consequência de uma cultura patriarcal, que até os dias atuais influencia a determinação das funções dos membros da família (HALBERSTADT; DE SOUZA, 2020).

Nesta pesquisa, a maior incidência das crianças e adolescentes com autismo era (257) do sexo masculino, o que coaduna com a literatura e com dados da Organização Mundial de Saúde (NOGUEIRA; DA SILVA RUSCH; DA SILVA ALVES, 2021; BOTTAN et al., 2020).

As rendas, apesar de variarem, acompanham o que acontece no Brasil, já que apenas $15 \%$ da população encontra-se nas classes A e B (IBGE, 2018). Já a porcentagem de 22,7\% receber um salário-mínimo pode estar relacionada a um fato não tão incomum no Brasil, que é viver com o Benefício de Prestação Continuada (BPC), pago pelo governo federal. Como foi observado na pesquisa, 55,65\% tiveram diminuição de renda durante a quarentena, o que já trará mudanças nas rotinas das famílias.

Com a pandemia, as escolas foram fechadas, assim, 311 (96,60\%) participantes, do total de 322 , que estudam pararam de frequentar a escola, além das atividades extraescolares terem sido radicalmente reduzidas. Com as escolas fechadas, as famílias assumiram as responsabilidades com o ensino, neste caso apoiadas pela escola. Porém, sabe-se que a relação família-escola não é simples e depende da disponibilidade, tanto da escola, nas figuras da direção, coordenação e professores, quanto das famílias. Esta relação é construída com participação, reconhecimento dos diferentes saberes, respeito mútuo e diálogo aberto (MORENO, 2018).

Merece destaque o fato de ter sido radicalmente reduzido o número de crianças e adolescentes nas terapias de suporte, destacando a terapia fonoaudiológica, a terapia ocupacional e o acompanhamento psicológico.

A mudança de rotina e a ausência de suporte para essas crianças e adolescentes inevitavelmente gerou maior sobrecarga das famílias. Estudos como de Halberstadt, Moares e Souza, (2020), Tsukamoto et al. (2010), ressaltam a importância do suporte a pais de pessoas com deficiência. Os apoios profissionais contribuem para que os pais ou cuidadores possam desenvolver recursos internos para enfrentar as dificuldades. Especialmente o diálogo dos pais 
com professores e terapeutas das crianças e adolescentes contribuem para que os pais aprendam a lidar com as variadas demandas, comuns em casos de pessoas com autismo.

Outros estudos mostraram que o processo de cuidado de pessoas com deficiência torna-se mais suave quando há o envolvimento de profissionais nas distintas necessidades, como de acolhimento, acompanhamento e orientação (MESQUITA et al., 2020).

Com o fechamento das escolas os alunos também ficaram sem o Atendimento Educacional Especializado (AEE), que é outro dispositivo importante de apoio pedagógico às crianças e adolescentes com autismo. Segundo as diretrizes da Política Nacional de Educação Especial na Perspectiva da Educação Inclusiva, o AEE é responsável pela organização dos recursos pedagógicos e pela eliminação das barreiras que impeçam esse aluno de aprender (GONÇALVES; MANTOVANI; MACALLI, 2016).

O autismo, sendo visto em sua dimensão biopsicossocial, invoca outro olhar sobre as questões relacionadas à qualidade de vida e sobre as implicações vindas do processo de deficiência. As famílias estando sozinhas no processo de cuidado perdem, além do apoio profissional, a partilha entre os pais e/ou cuidadores. Por isso, ficam mais estressadas, sentemse desamparadas e acabam por ter mais dificuldade na regulação social (CIPRIANO et al., 2020).

Como pode ser visto nos resultados, antes do distanciamento social as crianças executavam diversas atividades de lazer, e com o distanciamento social essas atividades foram reduzidas, sendo as crianças obrigadas a brincar dentro de casa ou no quintal, jogar no celular ou tablet, desenhar e assistir televisão. Além disso, ficaram, na sua maioria, brincando sozinhas ou brincando com adultos. Sabe-se que as relações sociais são de extrema importância para o desenvolvimento da criança e para que as famílias reconheçam as necessidades e se engajem nas relações afetivas e sociais (BISPO DOS SANTOS et al., 2020).

Outro fator que merece discussão é que todas as mudanças provocadas pelo distanciamento social também geraram alterações no comportamento. Das mudanças apontadas, $221(68,6 \%)$ participantes avaliaram essas mudanças como negativas, e 101 (31,4\%) como positivas. Outros estudos, como de Colizzi et al. (2020), demonstraram que a situação pandêmica fez com que sintomas relacionados a questões mentais e psicológicas preexistentes fossem agravados.

No caso dos transtornos do espectro do autismo (TEA), em que há um grupo com condições diferentes de comportamento, comunicação, linguagem e interação social, o distanciamento social pode gerar estresse e ansiedade, o que pode interferir negativamente no 
comportamento (LIMA; SANTOS; MONTEIRO, 2021). Porém, segundo nossos dados, $31,4 \%$ das famílias avaliaram que as mudanças das crianças e adolescentes com autismo foram positivas. Ao analisar o porquê desta situação, entende-se que como os autistas, habitualmente, tem preferência por ambientes previsíveis, ficar em casa pode ter trazido certo conforto e segurança (HODGES; FEALKO; SOARES, 2020).

Resultados desta pesquisa indicam que a maioria dos pais considera que o período de restrições causado pela pandemia da Covid-19 afetou o comportamento da maioria das crianças e adolescentes com autismo $(68,6 \%)$. Outros estudos também verificaram que as famílias se sentiram sobrecarregadas durante a pandemia, com dificuldades em organizar as atividades diárias. Além disso, percebeu-se que pessoas com TEA são mais vulneráveis à interrupção da rotina, e tiveram uma piora no comportamento (COLIZZI et al., 2020).

Em relação à linguagem e comunicação, serão analisadas cada uma das temáticas separadamente. A primeira temática, interação, dizia respeito ao modo como estavam brincando e interagindo. Um pouco mais da metade dos respondentes $(53,30 \%)$ apontaram as mudanças de interação como negativa, e o restante $(46,70 \%)$ como positivas. A avaliação negativa do aspecto interacional durante a pandemia da Covid-19 é apontada em outros estudos com pessoas com TEA. Colizzi et al. (2020) afirmaram que as famílias cujos filhos têm autismo experimentam maior estresse do que outras famílias, reverberando no modo como interagem com seus filhos. Smile (2020) constatou que as crianças com autismo podem aumentar a dificuldade na interação por não se adaptarem a esta nova norma.

Já em relação ao impacto positivo do distanciamento social na interação de crianças e adolescentes com autismo pode-se analisar que parte das famílias aproveitou o distanciamento social e o fato de todos estarem em casa para intensificar os momentos de interação. Entendese aqui que a interação e o diálogo são resultado do encontro intenso e recíproco entre as pessoas (GENU SOARES et al., 2019).

Outro fator verificado em outros trabalhos é que em países de maior estrutura os pais receberam maior suporte para enfrentar o distanciamento social, nestes casos os pais envolveram seus filhos com autismo em diferentes atividades em casa, receberam um guia de atividades para desenvolverem com os filhos, e aproveitaram este momento para ensinarem às crianças novos comportamentos sociais (CAHAPAY, 2020).

Quanto à segunda temática, características paralinguísticas (contato visual e expressão facial), a grande maioria dos respondentes (70,35\%) disse que as crianças e adolescentes estavam com mais contato visual e mais expressão facial; e $89(29,65 \%)$ apontaram que as crianças e adolescentes estavam com menos contato visual e menos expressão facial. Uma 
hipótese para esta melhora é que pelo fato de estarem convivendo apenas com pessoas muito próximas, as habilidades paralinguísticas seriam mais facilmente percebidas e as crianças estariam mais à vontade para se expressarem. Não foram encontrados estudos que avaliassem esse aspecto durante o distanciamento social, porém, em um estudo com adolescentes e adultos com autismo constatou-se que um dos motivos de evitarem o contato visual deve-se ao fato de terem dificuldades em compreender como usá-lo de forma adequada socialmente, e em inferir e enviar informações emocionais não verbais. Sendo assim, é possível que se sintam menos ameaçados com pessoas próximas e por isso façam mais contato visual (TREVISAN; ROBERTS; BIRMINGHAM, 2017).

$\mathrm{Na}$ terceira temática, que envolvia de forma mais direta a linguagem e a comunicação, os resultados mostraram que metade dos participantes avaliaram que durante o distanciamento social as crianças e adolescentes tinham melhorado neste quesito, e metade que pioraram.

Sabe-se que a linguagem é uma atividade que envolve complexos sistemas, e profissionais de diferentes áreas podem contribuir para diagnóstico, planejamento e tratamento para os diferentes tipos de problemas (FERNANDES; DEFANI, 2013). Portanto, o fato das crianças e adolescentes estarem sem acompanhamento terapêutico e escolar, provavelmente, é um dos motivos da pandemia ter tido um impacto negativo na comunicação. Estudos mostraram que quando há compartilhamento entre as famílias, ou grupos de apoio, diminui-se o medo e a insegurança (COLIZZI et al., 2020; DIAS et al., 2021). Tanto as famílias quanto as próprias crianças e adolescentes com autismo precisam de apoio, especialmente neste momento de pandemia, para dar continuidade aos processos de desenvolvimento e aprendizagem (BONOTTO et al., 2020).

Outro fator que justifica o impacto negativo na linguagem e comunicação, durante o distanciamento social, é o fato de que as crianças e adolescentes reduziram de forma drástica os processos interacionais e as trocas comunicativas. Os processos de interação e de comunicação entre a criança com autismo e outras crianças e os adultos contribuem para o desenvolvimento da linguagem, bem como de outras manifestações expressivas. Estar em grupo potencializa a dinâmica dialógica e outras formas de contato e interação (OLIVEIRA; VICTOR, 2018).

Quanto às famílias que avaliaram que, durante o distanciamento social, as crianças e adolescentes com autismo tiveram uma melhora na linguagem e na comunicação, nossa hipótese é que essas famílias conseguiram garantir o apoio a seus filhos, e que dessa forma a proximidade com a família, o ambiente conhecido e a rotina familiar seriam facilitadoras do 
desenvolvimento da linguagem. Isto se deve ao fato de executarem atividades mais tranquilas e com menos conflitos (AMARAL; VRIES, 2020).

\section{Conclusão}

O desenvolvimento de pesquisas com crianças e adolescentes com autismo neste momento de pandemia é de extrema importância, por se constituírem um grupo vulnerável. As pessoas com autismo necessitam de um aparato de cuidados, e a pandemia, com o consequente distanciamento social, tem impedido atendimentos clínicos e educacionais.

Surtos de infecções, como da Covid-19, podem provocar medo e insegurança, especialmente em pessoas vulneráveis. Portanto, pode-se concluir que na pandemia da Covid19 os agravos dos impactos negativos do distanciamento social nas crianças e adolescentes com autismo também foi percebido na comunicação. Além disso, as famílias dessas crianças parecem estar mais sujeitas ao estresse (COLBERT, 2020; COLIZZI et al., 2020; DROGOMYRETSKA; FOX).

Como pontos fortes dessa pesquisa, podem-se citar o número de participantes; a resposta rápida; a objetividade do estudo; e a similaridade com os resultados de outros estudos. O estudo também apresentou limitações, como a variabilidade de características e o grau de severidade do autismo nos participantes; possíveis dificuldades das famílias em responder; a impossibilidade de cruzamento entre algumas varáveis do estudo, como renda e comunicação.

Inegavelmente, a emergência da Covid-19 em curso trouxe desafios de diferentes áreas, como a econômica, política, educacional, da saúde e pessoal (MORALES et al., 2021). Afetou diversos grupos, dentre eles os das crianças e adolescentes com autismo. Como síntese dos resultados desta pesquisa, conclui-se que a grande maioria das crianças e adolescentes com autismo apresentaram mudanças de comportamento; as alterações de comportamento foram avaliadas como negativas pela maioria das famílias; a interação também apresentou mudanças, sendo que em proporção semelhante para as mudanças negativas e positivas; as características paralinguísticas sofreram um impacto negativo; e a linguagem e comunicação sofreram alterações, sendo que praticamente metade dos respondentes afirmou que a linguagem e a comunicação estava pior e a outra metade melhor; que a escola é um importante fator para o desenvolvimento da interação e que impulsiona a comunicação..

A pandemia da Covid-19 ainda é uma realidade em diversos países, dentre eles o Brasil, e os resultados apontam para a necessidade de diferentes tipos de apoio para as 
crianças e adolescentes com autismo e para suas famílias, incluindo o suporte educacional e de saúde. No Brasil, mesmo antes da pandemia, as questões relacionadas à intersetorialidade nas políticas apresentam muitas falhas, e no caso da pessoa com deficiência somente a transversalidade pode suprir as variadas demandas (GIVIGI et al., 2020). Através dos resultados de pesquisa é possível a delimitação de medidas reparadoras, contribuindo com a melhoria na qualidade de vida de crianças e adolescentes com autismo e consequentemente para suas famílias.

\section{REFERÊNCIAS}

AMARAL, D. G.; VRIES, P. J. COVID-19 and Autism Research: Perspectives from Around the Globe. Autism research, v. 13, n. 6, p. 844-869. DOI: https://doi.org/10.1002/aur.2329

\section{AMERICAN PSYCHIATRIC ASSOCIATION. Diagnostic and Statistical Manual of} Mental Disorders, Fifth Edition (DSM-V). Arlington, VA: American Psychiatric Association, 2013.

BISPO DOS SANTOS, I. et al. Qualidade de vida de surdos usuários de libras no sul do Brasil. Saúde e Pesquisa, v. 13, n. 2, 2020. DOI: https://doi.org/10.17765/21769206.2020v13n2p295-307

BONOTTO, R. et al. Oportunidades de aprendizagem com apoio da Comunicação Aumentativa e Alternativa em tempos de COVID-19. Revista Ibero-Americana de Estudos em Educação, Araraquara, v. 15, n. 4, p. 1730-1749, 2020. DOI: https://doi.org/10.21723/riaee.v15i4.13945

BOTTAN, G.P. et al. Analisar a alimentação de autistas por meio de revisão de literatura. Braz J of Develop, v. 6, n. 12, p. 100448-100470, 2020. Disponível em: https://doi.org/10.34117/bjdv6n12-512

BRIET, G. et al. Longitudinal assessment of children with autism spectrum disorders receiving intensive educational intervention in mainstream school setting. In:

INTERNATIONAL ESCAP CONGRESS, 17., 2017, Genève. Proceedings [...]. Genève, 2017. Disponível em: https://hal.archives-ouvertes.fr/hal-01728970/. Acesso em: 10 jun. 2021.

CAHAPAY, M. B. How Filipino parents home educate their children with autism during COVID-19 period. Int J Dev Disabil., p. 1-4, 2020. DOI:

https://doi.org/10.1080/20473869.2020.1780554

CIPRIANO, J.P.S. et al. Estrutura representacional da microcefalia e autoimagem de mães de crianças com tal condição neurológica. Saúde e pesqui., v. 13, n. 3, p. 631-643. DOI: https://doi.org/10.17765/2176-9206.2020v13n3p631-643 
COLIZZI, M. et al. Psychosocial and behavioral impact of COVID-19 in autism spectrum disorder: an online parent survey. Brain Sci., v. 10, n. 6, p. 341, 2020. Disponível em: https://doi.org/10.3390/brainsci10060341.

CONSELHO FEDERAL DE FONOAUDIOLOGIA. Recomendação CFFa n. 19, de 19 de março de 2020. Brasília (DF): Conselho Federal de Fonoaudiologia, 19 mar. 2020.

Disponível em: https://www.fonoaudiologia.org.br/cffa/wp-

content/uploads/2020/03/Recomendacao_CFFa_19_2020.pdf. Acesso em: 08 jun. 2020.

DIAS, M. D. P. et al. Desenvolvimento de grupo educativo de nutrição para mulheres na atenção primária à saúde. Saúde e Pesquisa, v. 14, n. 1, 2021.

DIAS-TRINDADE, S.; CORREIA, J. D.; HENRIQUES, S. Ensino remoto emergencial na educação básica brasileira e portuguesa: a perspectiva dos docentes. Revista Tempos e Espaços em Educação, v. 13, n. 32, p. 1-23, 21 nov. 2020. DOI:

https://doi.org/10.20952/revtee.v13i32.14426

DROGOMYRETSKA, K.; FOX, R.; COLBERT, D. Brief Report: Stress and Perceived Social Support in Parents of Children with ASD. Journal of Autism \& Developmental Disorders, v. 50, n. 11, 2020.

FERNANDES, R.; DEFANI, M. A. Importância da equipe multidisciplinar no tratamento e proservação de fissuras labiopalatinas. Saúde e pesqui., v. 6, n. 1, p. 109-116, 2020.

FIOCRUZ. Fundação Oswaldo Cruz. Boletim indica adoção de medidas rígidas para bloqueio da Covid-19. Rio de Janeiro: Fundação Oswaldo Cruz; 23 mar. 2021. Disponível em: https://portal.fiocruz.br/noticia/boletim-indica-adocao-de-medidas-rigidas-para-bloqueioda-covid-19. Acesso em: 10 jun. 2021.

GENU SOARES, M. et al. A Filosofia relacional dialógica e as perspectivas do interculturalismo na educação. Revista Tempos e Espaços em Educação, v. 12, n. 30, p. 275-290, 8 ago. 2019. DOI: https://doi.org/10.20952/revtee.v12i30.11124

GIVIGI, R. C. N. et al. Políticas educacionais inclusivas e a intersetorialidade com as políticas sociais: interfaces Brasil/Canadá. Revista Ibero-Americana de Estudos em Educação, Araraquara, v. 15, n. esp3, p. 2240-2259, 2020. DOI: 10.21723/riaee.v15iesp3.14429. Disponível em: https://periodicos.fclar.unesp.br/iberoamericana/article/view/14429. Acesso em: 24 set. 2021.

GONÇALVES, T. G. G. L.; MANTOVANI, J. V.; MACALLI, A. C. Atendimento educacional especializado: reflexões da realidade de um município paulista. Revista IberoAmericana de Estudos em Educação, Araraquara, v. 11, n. 1, p. 131-150, 2016. Disponível em: https://periodicos.fclar.unesp.br/iberoamericana/article/view/6178. Acesso em: 24 set. 2021.

HALBERSTADT, B. F.; MORAES, A.B.; SOUZA, A. P. R. Síndrome de Down: funcionalidade e histórico terapêutico da criança, adaptação e desempenho ocupacional dos pais. Saúde e pesqui., v. 13, n. 4, p. 809-819, 2020. DOI: https://doi.org/10.17765/21769206.2020v13n4p809-819 
HE, X. et al. Temporal dynamics in viral shedding and transmissibility of COVID-19. Nat Med., v. 26, p. 672-675, 2020. DOI: https://doi.org/10.1038/s41591-020-0869-5

HODGES, H.; FEALKO, C.; SOARES, N. Autism spectrum disorder: definition, epidemiology, causes, and clinical evaluation. Translational pediatrics, v. 9, n. suppl. 1, p. S55, 2020. DOI: https://doi.org/10.21037/tp.2019.09.09

IBGE. Pesquisa Nacional por Amostra de Domicílios Contínua: rendimento de todas as fontes: 2018. Rio de Janeiro: IBGE; 2018. Disponível em: https://www.ibge.gov.br > 17270pnad-continua. Acesso em: 10 jun. 2021.

JIAO, W.Y. et al. Behavioral and Emotional Disorders in Children during the COVID-19 Epidemic. J Pediatr., v. 221, p. 264-266.e1, 2020. DOI:

https://doi.org/10.1016/j.jpeds.2020.03.013

LAUER, S. et al. The incubation period of coronavirus disease 2019 (COVID-19) from publicly reported confirmed cases: estimation and application. Annals of internal medicine, v. 172, n. 9, p. 577-582, 2020. DOI: https://doi.org/10.7326/M20-0504

LEWNARD, J. A.; LO, N. C. Scientific and ethical basis for social-distancing interventions against COVID-19. Lancet Infect Dis., v. 20, n. 6, p. 631-633, 2020.

LIMA, Y. M.; SANTOS, T. R. L.; MONTEIRO, R. A. O. Between inclusion and exclusion: Teachers' reflections about students with autism in public school. Revista Tempos e Espaços em Educação, v. 14, n. 33, p. e14098, 24 maio 2021. DOI:

https://doi.org/10.20952/revtee.v14i33.14098

MESQUITA, K. O. D. et al. Envolvidos no cuidado: análise da segurança do paciente. Saúde e pesqui., v. 13, n. 3, p. 495-502, 2020. DOI: https://doi.org/10.17765/21769206.2020v13n3p495-502

MORALES, J. N. S. et al. Virtuality in university teaching-learning versus COVID19. Revista Tempos E Espaços Em Educação, v. 14, n. 33, p. e15108-e15108, 2021. DOI: http://dx.doi.org/10.20952/revtee.v14i33.15108

MORENO, G. L. A relação escola-família e a organização do trabalho pedagógico na educação infantil. Revista Ibero-Americana de Estudos em Educação, Araraquara, v. 13, n. 4, p. 1187-1203, 2018. Disponível em:

https://periodicos.fclar.unesp.br/iberoamericana/article/view/9778. Acesso em: 24 set. 2021.

NOGUEIRA, M. T. D.; DA SILVA RUSCH, F.; DA SILVA ALVES, G. D. G. Mães de Crianças com o Transtorno do Espectro Autista: Estresse e Sobrecarga. Revista Humanitaris-B3, v. 2, n. 2, p. p. 54-75, 2021.

OLIVEIRA, I. M.; VICTOR, S. L. A criança com autismo na brinquedoteca: percursos de interação e linguagem. Rev Educ Esp., v. 31, n. 62, p. 651-663, 2018. DOI:

http://dx.doi.org/10.5902/1984686X29281

OTTONI, A. C. V.; MAIA, A. C. B. Considerações sobre a sexualidade e educação sexual de pessoas com transtorno do espectro autista. Revista Ibero-Americana de Estudos em 
Educação, Araraquara, v. 14, n. esp.2, p. 1265-1283, 2019. Disponível em:

https://periodicos.fclar.unesp.br/iberoamericana/article/view/12575 Acesso em: 24 set. 2021.

SERGIPE. Decreto n. 40567, de 24 de março de 2020a. Atualiza, consolida e estabelece novas medidas de enfrentamento e prevenção à epidemia causada pelo COVID-19 (novo Coronavírus) no Estado de Sergipe, e dá outras providências. Diário Oficial do Estado, Aracaju, 25 mar. 2020. Disponível em: https://www.legisweb.com.br/legislacao/?id=391536. Acesso em: 10 jun. 2021.

SERGIPE. Boletim Epidemiológico para atualização sobre o COVID-19. Aracaju: Secretaria do Estado da Saúde. 7 jun. 2020b. Disponível em: https://todoscontraocorona.net.br/wp-content/uploads/2020/06/Boletim-07.06.2020.pdf. Acesso em: 10 jun. 2021.

SERGIPE. Portaria n. 273/2020. Aracaju: Secretaria de Estado da Saúde, 2020. Disponível em: https://todoscontraocorona.net.br/wp-content/uploads/2020/10/168679-Portaria-2732020_protocolo-sanitario-escolas.pdf. Acesso em: 10 jun. 2021.

SHAKESPEARE, T.; NDAGIRE, F.; SEKETI, Q. E. Triple jeopardy: disabled people and the COVID-19 pandemic. The Lancet., v. 397, n. 10282, p. 1331-1333, 2021. DOI:

https://doi.org/10.1016/S0140-6736(21)00625-5

SMILE, S.C. Supporting children with autism spectrum disorder in the face of the COVID-19 pandemic. CMAJ., v. 192, n. 21, p. E587-E587, 2020. DOI:

https://doi.org/10.1503/cmaj.75399

SOCIEDADE BRASILEIRA DE PEDIATRIA. Pais e filhos em confinamento durante a pandemia de COVID-19. Porto Alegre: Sociedade Brasileira de Pediatria, mar. 2020a. Disponível em: https://www.sbp.com.br/fileadmin/user_upload/22420cNAlerta_Pais_e_Filhos_em_confinamento_COVID-19.pdf. Acesso em: 10 jun. 2021.

\section{SOCIEDADE BRASILEIRA DE PEDIATRIA. Manual de Orientação: Transtorno do}

Espectro do Autismo. Departamento Científico de Pediatria do Desenvolvimento e Comportamento. Porto Alegre: Sociedade Brasileira de Pediatria, 2019. Disponível em: https://www.sbp.com.br > fileadmin > user_upload. Acesso em: 10 jun. 2021.

TREVISAN, D. A.; ROBERTS, N.; LIN, C.; BIRMINGHAM, E. How do adults and teens with self-declared autism spectrum disorder experience eye contact? A qualitative analysis of first-hand accounts. PLoS One., v. 12, n. 11, e0188446, 2017. DOI:

https://doi.org/10.1371/journal.pone.0188446

TSUKAMOTO, H.F. et al. A problemática do cuidador familiar: os desafios de cuidar no domicílio. Saúde e pesqui., v. 3, n. 1, p. 53-58, 2010.

WANG, G. et al. Mitigate the effects of home confinement on children during the COVID-19 outbreak. The Lancet., v. 395, n. 10228, p. 945-947, 2020. DOI:

https://doi.org/10.1016/S0140-6736(20)30547-X 
WORLD HEALTH ORGANIZATION. From Coronavirus disease (COVID-19)

pandemic. Genebra: WHO, 2021. Disponível em: https://www.who.int/covid-19. Acesso em: 10 jun. 2021.

\section{Como referenciar este artigo}

GIVIGI, R. C. N.; CUNHA, A. C. H.; BARRETO, L. L. A.; SILVA, G. S.; CONCEIÇÃO, L. C. Impactos do distanciamento social por Covid-19 na comunicação de crianças e adolescentes com autismo. Revista Ibero-Americana de Estudos em Educação, Araraquara, v. 16, n. 4, p. 2903-2921, out./dez. 2021. e-ISSN: 1982-5587. DOI: https://doi.org/10.21723/riaee.v16i4.15687

Submetido em: 01/08/2021

Revisões requeridas em: $25 / 09 / 2021$

Aprovado em: 01/10/2021

Publicado em: 21/10/2021 